\title{
Inhibition of chaperone-mediated autophagy reduces tumor growth and metastasis and promotes drug sensitivity in colorectal cancer
}

\author{
YING XUAN, SHUANG ZHAO, XINGJUN XIAO, LIWEI XIANG and HUA-CHUAN ZHENG
}

Department of Experimental Oncology, Shengjing Hospital of

China Medical University, Shenyang, Liaoning 110004, P.R. China

Received September 16, 2020; Accepted February 18, 2021

DOI: $10.3892 / \mathrm{mmr} .2021 .11999$

\begin{abstract}
Chaperone-mediated autophagy (CMA) is a selective type of autophagy whereby a specific subset of intracellular proteins is targeted to the lysosome for degradation. The present study investigated the mechanisms underlying the response and resistance to 5-fluorouracil (5-FU) in colorectal cancer (CRC) cell lines. In engineered 5-FU-resistant CRC cell lines, a significant elevation of lysosome-associated membrane protein $2 \mathrm{~A}$ (LAMP2A), which is the key molecule in the CMA pathway, was identified. High expression of LAMP2A was found to be responsible for 5-FU resistance and to enhance PLD2 expression through the activation of NF- $\mathrm{kB}$ pathway. Accordingly, loss or gain of function of LAMP2A in 5-FU-resistant CRC cells rendered them sensitive or resistant to 5-FU, respectively. Taken together, the results of the present study suggested that chemoresistance in patients with CRC may be mediated by enhancing CMA. Thus, CMA is a promising predictor of chemosensitivity to 5-FU treatment and anti-CMA therapy may be a novel therapeutic option for patients with CRC.
\end{abstract}

\section{Introduction}

Colorectal cancer (CRC) is one of the most frequent causes of cancer-related deaths worldwide (1). Its carcinogenesis is a multistep process and the molecular mechanisms of its

Correspondence to: Professor Hua-Chuan Zheng, Department of Experimental Oncology, Shengjing Hospital of China Medical University, 36 Sanhao Street, Heping, Shenyang, Liaoning 110004, P.R. China

E-mail: zheng_huachuan@hotmail.com

Abbreviations: CMA, chaperone-mediated autophagy; CRC, colorectal cancer; 5-FU, 5-fluorouracil; CQ, clioquinol; PDTC, pyrrolidine dithiocarbamate; OXA, oxaliplatin; DMSO, dimethyl sulfoxide; shRNA, short hairpin RNA

Key words: chaperone-mediated autophagy, lysosome-associated membrane protein 2A, colorectal cancer, drug resistance, $\mathrm{NF}-\kappa \mathrm{B}$ p65 pathway, 5-fluorouracil development and metastasis remain elusive (2). Although some improvements have been made in early diagnosis and systemic therapies, only $\sim 50 \%$ of patients with CRC survive for at $\geq 5$ years following diagnosis (3). Chemotherapeutic drugs can significantly inhibit the progression of CRC, but drug resistance remains a major cause of failure in chemotherapy regimens $(4,5)$.

Chaperone-mediated autophagy (CMA) is a highly selective form of autophagy for cellular quality control (6). During CMA, the heat shock cognate protein 70 (HSC70) chaperone carries target proteins endowed with a certain KFERQ-like motif to the lysosome-associated membrane protein $2 \mathrm{~A}$ (LAMP2A), which then translocates them into lysosomes for degradation (6,7). LAMP2A is the best criterion to determine whether protein degradation occurs via CMA (8). CMA is activated in multiple types of cancers such as breast $(9,10)$, colorectal (11), gastric (12) and liver (13) cancer which demonstrates that LAMP2A overexpression contributes to tumor growth and metastasis. In addition, CMA is reported to be associated with the resistance to anticancer therapy $(11,14)$.

Phospholipase D (PLD) is an enzyme that catalyzes the hydrolysis of phosphatidylcholine, the most abundant phospholipid in eukaryotic cell membranes, to produce phosphatidic acid (PA) and choline (15). PA is the second messenger that can be metabolized to other lipid metabolites, such as lyso-PA and diacylglycerol (16). A total of two mammalian isoforms of PLD have been described; PLD1 and PLD2, which are almost ubiquitous and share $\sim 50 \%$ homology $(17,18)$. PLD2 overexpression increases proliferation, adhesion, invasion and metastasis in a wide variety of cancers including gastric, colorectal, renal, stomach, lung and breast cancers $(16,19-22)$. In addition, it has been reported that PLD2 is associated with multidrug resistance in human cancer cells (23).

To obtain insights into the mechanism of 5-FU resistance in CRC cells, the present study constructed 5-FU-resistant HCT116 and DLD-1 cells from parental HCT116 and DLD-1 cell lines. It demonstrated that HCT116R/DLD-1-R cells exhibited a drastic elevation of LAMP2A and this resulted in enhanced PLD2 expression through the activation of the NF- $\mathrm{kB}-\mathrm{p} 65$ pathway. Accordingly, loss or gain of function of LAMP2A in 5-FU resistant CRC cells rendered them sensitive or resistant to 5-FU, respectively. 


\section{Materials and methods}

Cell culture and reagents. HCT-116, DLD-1 and NCM460 cell lines were obtained from Professor Miyagi Yohei (Clinical Research Institute, Kanagawa Cancer Center, Yokohama, Japan). The cell lines were cultured as monolayers in RPMI-1640 medium (Thermo Fisher Scientific, Inc.) supplemented with $10 \%$ fetal bovine serum (FBS; Thermo Fisher Scientific, Inc.) with $100 \mathrm{U} / \mathrm{ml}$ penicillin and $100 \mu \mathrm{g} / \mathrm{ml}$ streptomycin at $37^{\circ} \mathrm{C}$ in a humidified atmosphere containing $5 \% \mathrm{CO}_{2}$. All cells were harvested by centrifugation $(1,500 \mathrm{x} \mathrm{g}$ for $10 \mathrm{~min}$ at $4^{\circ} \mathrm{C}$ ) and rinsed with phosphate-buffered saline (PBS). Anti-LAMP2A (cat. no. ab18528) and anti-PLD2 (cat. no. ab78907) antibodies were purchased from Abcam. NF-кB Pathway Sampler kit (cat. no. 9936T) was purchased from Cell Signaling Technology, Inc. Anti-cluster of differentiation (CD)147/extracellular matrix metalloproteinase inducer (EMMPRIN; cat. no. SC-21746) antibody was purchased from Santa Cruz Biotechnology, Inc. Anti-lung resistance-related protein 1 (LRP1; cat. no. ab92544), anti-P-glycoprotein 1 (PGP)/multidrug resistance (MDR; cat. no. ab242104), anti-glutathione S-transferase $\pi$ (GST- $\pi$; cat. no. ab138491), anti-MutL homologue 1 (MLH1; cat. no. ab92312), Anti-F-box and WD40 domain protein 7 (FBXW7) antibody (cat. no. ab12292) and anti-multidrug resistance-associated protein 1 (MRP1; cat. no. ab233383) antibodies were purchased from Abcam. Anti-Bcl-2 (cat. no. 15071) and anti-BAX (cat. no. 14796) antibodies were purchased from Cell Signaling Technology, Inc. LysoTracker-LysoGreen was purchased from Nanjing KeyGen Biotech Co., Ltd. (cat. no. KGMP006-2). Pyrrolidine dithiocarbamate (PDTC; cat. no. P8765.) and chloroquine (CQ; cat. no. C6628.) were purchased from Sigma-Aldrich (Merck KGaA) and 5-fluorouracil (5-FU) was purchased from Shanghai Xudong Haipu Pharmaceutical Co., Ltd. Oxaliplatin (OXA) was purchased from Nanjing Pharmaceutical Factory, Co. Ltd.

Cell viability assay. Cell viability was measured using the MTT assay. CRC and 5-FU-resistant CRC cells were seeded in triplicate in 96-well plates at 6,000 cells/well and incubated at $37^{\circ} \mathrm{C}$ for $24 \mathrm{~h}$ in RPMI-1640 medium supplemented with $10 \%$ FBS. Subsequently, the cells were treated with the indicated doses of 5-FU $(10 \mathrm{mM})$, OXA $(10 \mathrm{mM})$, or FOX (5-FU: $10 \mathrm{mM}+$ OXA: $10 \mathrm{mM}$ ) for $96 \mathrm{~h}$ at $37^{\circ} \mathrm{C}$. The same volume of dimethyl sulfoxide (DMSO) was used as the negative control. Following this, $25 \mu \mathrm{l}$ MTT solution $(5 \mathrm{mg} / \mathrm{ml})$ was added to each well for $4 \mathrm{~h}$ at $37^{\circ} \mathrm{C}$, then the cell culture supernatants were carefully removed and $200 \mu \mathrm{l}$ DMSO was added to dissolve the purple formazan. Finally, the optical density was measured at a wavelength of $570 \mathrm{~nm}$ using a microplate reader (Model 550; Bio-Rad Laboratories, Inc.).

Cell migration and invasion assays. For the migration assay, $2 \times 10^{5}$ cells were resuspended in serum-free RPMI-1640 and seeded in the Matrigel-coated insert (BD Biosciences) insert on the top portion of the chamber (BD Biosciences). The lower compartment of the chamber contained 10\% FBS as a chemoattractant. After incubation for $24 \mathrm{~h}$, cells on the membrane were scrubbed, washed with PBS, fixed in $100 \%$ methanol for $10 \mathrm{~min}$ at room temperature and stained with $10 \%$ Giemsa dye for $10-15 \mathrm{~min}$ at room temperature. For the invasive assay, the procedures were the same as above with a control-membrane insert (BD Biosciences). A total of five random fields were selected to count and images were captured under an inverted fluorescence microscope (x10 magnification; Nikon Corporation).

Quantification of apoptosis by flow cytometry. Flow cytometry was performed with 7-aminoactinomycin and phycoerythrin labeled Annexin V (BD Pharmingen; BD Biosciences) to detect phosphatidylserine externalization as an endpoint indicator of apoptosis. Cell apoptosis was detected by staining with Annexin V-PE/7AAD (KeyGen Biotech Co., Ltd.; cat. no. KGA214) according to the manufacturer's instructions. Apoptotic rate was calculated by the percentage of early + late apoptotic cells. After washing with PBS and centrifuging twice (both $1,000 \times \mathrm{g}, 5 \mathrm{~min}$ ), cells were resuspended in Annexin-V binding buffer. They were stained with Annexin V-PE/7AAD and incubated for another $15 \mathrm{~min}$ at room temperature in a dark room. Cell samples were analyzed by flow cytometry (FACScan; BD Biosciences) to acquire the apoptotic fractions. Apoptotic fractions were investigated by Cell Quest 3.0 software (BD Biosciences).

Cell transfection. The short hairpin (sh)RNA and LAMP2A expression plasmids were designed, constructed and purified by Shanghai GenePharma Co., Ltd. The shRNA and LAMP2A expression plasmids were transfected using Attractene Transfection Reagent (Qiagen $\mathrm{GmbH}$ ) in accordance with the manufacturer's instructions. Cells cultured in 6-well plates were transfected with $1.2 \mathrm{ug} /$ well shRNA or LAMP2A expression plasmids. At $24 \mathrm{~h}$ after transfection, the cells were collected to extract RNA and total protein for subsequent experimentation.

RNA extraction. Total RNA was extracted from cultivated cells using TRIzol ${ }^{\circledR}$ reagent (Thermo Fisher Scientific, Inc.) in accordance with the manufacturer's protocols. RNA purification was performed using the RNeasy Mini kit (Qiagen $\mathrm{GmbH}$ ) according to the manufacturer's instructions.

Reverse transcription-quantitative (RT-q) PCR. Total RNA was extracted from CRC cells $\left(1 \times 10^{6}\right)$ using the Qiagen RNeasy Mini kit (Qiagen $\mathrm{GmbH}$ ), according to the manufacturer's protocols. Total RNA was subjected to cDNA synthesis using avian myeloblastosis virus reverse transcriptase and random primer (Takara Bio, Inc.). General- and RT-qPCR amplification was performed using TaKaRa Hot Start Taq Polymerase (Takara Bio, Inc.) and SYBR Premix Ex Taq TM II kit (Takara Bio, Inc.), respectively, all according to the manufacturer's protocols. All experiments were performed three times. mRNA expression analysis was performed using SYBR Green Master Mix (Life Technologies; Thermo Fisher Scientific, Inc.) on a LightCycler 96 Detection system (Roche Diagnostics) using $\beta$-actin for normalization. The cycling parameters were: $95^{\circ} \mathrm{C}$ for $5 \mathrm{~min}$, followed by 59 cycles at $95^{\circ} \mathrm{C}$ for $30 \mathrm{sec}$, annealing at $55^{\circ} \mathrm{C}$ for $30 \mathrm{sec}$ and extension at $72^{\circ} \mathrm{C}$ for $30 \mathrm{sec}$. Expression levels were normalized to endogenous controls and relative quantification $\left(2^{-\Delta \Delta \mathrm{C} q}\right)$ was used for fold-change calculation (24). Using GenBank, oligonucleotide 
primers were designed as follows: LAMP2A: Forward primer: 5'-GCCGTTCTCACACTGCTCTA-3'; reverse primer: 5'-CCG CTATGGGCACAAGGAA-3'. PLD2: Forward primer: 5'-CCA CAAACAGGGGTGGTGTT-3'; reverse primer: 5'-GAATGG CCTGGATGGAGTTG-3'; $\beta$-actin: Forward primer: 5'-GGT GGCTTTTAGGATGGCAAG-3'; reverse primer: 5'-ACT GGAACGGTGAAGGTGACAG-3'.

Western blot analysis. Cells were lysed in SDS cell lysis buffer containing $50 \mathrm{mM}$ Tris (pH, 8.1) and 1\% SDS, supplemented with protease inhibitors (Roche Diagnostics) for $30 \mathrm{~min}$ on ice. The homogenates were centrifuged at $18,000 \mathrm{x} \mathrm{g}$ for $10 \mathrm{~min}$ at $4^{\circ} \mathrm{C}$. Supernatants were collected, and the protein concentration was determined by Bradford's assay (Bio-Rad Laboratories, Inc.); $30 \mu \mathrm{g}$ protein was loaded for analysis. The proteins were separated via $12 \%$ SDS-PAGE and electrotransferred onto a PVDF (polyvinylidene fluoride) membrane, which was then blocked overnight in 5\% skimmed milk in Tris-buffered saline with Tween-20 (TBST, $10 \mathrm{mM}$ Tris- $\mathrm{HCl}, 150 \mathrm{mM} \mathrm{NaCl}$, $0.1 \%$ Tween-20) at $4^{\circ} \mathrm{C}$. For immunoblotting, the membrane was incubated with primary antibody (all 1:1,000) for $2 \mathrm{~h}$ at room temperature $\left(20^{\circ} \mathrm{C}\right)$ as follows: LAMP2A, PLD2, NF- $\mathrm{KB}$, Bcl-2, BAX, MRP1, PGP, CD147, FBXW7, MLH1, LRP1 and GST $\pi$. Then, it was incubated with anti-rabbit or anti-mouse IgG antibodies conjugated to horseradish peroxidase (Dako; Agilent Technologies, Inc.) at a dilution of 1:5,000 for $2 \mathrm{~h}$ at room temperature. The bands were visualized using ECL-Plus detection reagents (Santa Cruz Biotechnology, Inc.). The densitometric quantification was performed with $\beta$-actin $(1: 1,000$; Santa Cruz Biotechnology, Inc.; cat. no. sc-47778) control using - ImageJ software (ImageJ 1.52a; National Institutes of Health).

Co-immunoprecipitation. CRC cells $\left(1 \times 10^{7}\right)$ were seeded onto $100 \mathrm{~mm}$ plates and allowed to attach overnight at $37^{\circ} \mathrm{C}$. The cells were then washed twice with PBS and lysed in lysis buffer (1\% Triton X-100, $50 \mathrm{mM}$ Tris-HCl pH 7.4, $150 \mathrm{mM}$ $\mathrm{NaCl}, 10 \mathrm{mM}$ EDTA, $100 \mathrm{mM} \mathrm{NaF}, 1 \mathrm{mM} \mathrm{Na} \mathrm{VO}_{4}, 1 \mathrm{mM}$ phenylmethylsulfonyl fluoride and $2 \mu \mathrm{g} / \mathrm{ml}$ aprotinin) on ice. Co-immunoprecipitation was performed using $200 \mu \mathrm{g}$ lysates with $4 \mu \mathrm{l}$ of rabbit anti- NF- $\mathrm{BB}$ or control IgG mixed with protein $\mathrm{G}$ agarose beads (GE Healthcare Bio-Sciences). The final mixture was gently agitated overnight at $4^{\circ} \mathrm{C}$. Following this, the beads were centrifuged for $1 \mathrm{~min}$ at $13,000 \mathrm{x}$ g at $4^{\circ} \mathrm{C}$ and washed four times with lysis buffer for $1 \mathrm{~min}$. Finally, $40 \mu \mathrm{l}$ sampling buffer (Beyotime Institute of Biotechnology) was added, boiled at $95^{\circ} \mathrm{C}$ for $5 \mathrm{~min}$ and subjected to western blot analysis. A total of $30 \mu \mathrm{g}$ protein was loaded for analysis. The proteins were separated via 10\% SDS-PAGE and transferred onto a PVDF membrane, which was then blocked overnight in $5 \%$ skimmed milk in TBST $(10 \mathrm{mM}$ Tris- $\mathrm{HCl}, 150 \mathrm{mM} \mathrm{NaCl}$, $0.1 \%$ Tween-20) at $4^{\circ} \mathrm{C}$. For immunoblotting, the membrane was incubated with primary antibodies (all 1:1,000) for $2 \mathrm{~h}$ at room temperature $\left(20^{\circ} \mathrm{C}\right)$ as follows: LAMP2A, PLD2, NF- $\mathrm{B}$, MRP1, PGP, CD147, FBXW7, MLH1, LRP1 and GST $\pi$. Then, it was incubated with anti-rabbit or anti-mouse IgG antibodies conjugated to horseradish peroxidase (Dako; Agilent Technologies, Inc.) at a dilution of 1:5,000 for $2 \mathrm{~h}$ at room temperature. The bands were visualized using ECL-Plus detection reagents (Santa Cruz Biotechnology, Inc.). The densitometric quantification was performed with $\beta$-actin $(1: 1,000$;
Santa Cruz Biotechnology, Inc.; cat. no. sc-47778) control using ImageJ software (version 1.52a; National Institutes of Health).

Statistical analysis. All statistical analyses were performed by SPSS v24.0 (IBM Corp.) with the Student's t-test (two tailed) and by one-way analysis of variance with Tukey's post hoc test for multiple groups. The results are representative of three different experiments and data are expressed as mean \pm standard deviation. $\mathrm{P}<0.05$ was considered to indicate a statistically significant difference.

\section{Results}

Establishment of 5-FU-resistant human CRC cell line. To obtain 5-FU-resistant cells, CRC cells were first selected using increasing concentrations of 5-FU on parental HCT-116/DLD-1 cells. They were then intermittently treated with large doses of 5-FU. Cells that acquired 5-FU resistance were identified by cell survival assay and showed increased expression of drug resistance proteins, CD147/ EMMPRIN (25); LRP1 (26); PGP/MDR (26); GST- $\pi$ (27); MLH1 $(28,29)$; MRP1 (26); FBXW7 (30), as verified by western blotting. They were labeled as HCT116-R or DLD-1-R cells (Fig. 1A-D). HCT116-R or DLD-1-R cells increased in size and the nuclei were irregular. Some cells had multiple, enlarged lysosomes. The proliferation rate of HCT116-R or DLD-1-R cells was similar to the parental cells, but the doubling time was prolonged in vitro (Fig. 1A and B). Co-resistance to other chemotherapy drugs such as OXA were also observed in HCT116-R or DLD-1-R cells (Fig. 1E).

LAMP2A is highly expressed in human CRC cell lines. Compared to parental cells, a significant elevation of LAMP2A was found in HCT116-R/DLD-1-R cells. However, the expression of LAMP2A was minimal in their corresponding normal colonic epithelial cells, NCM460 (Fig. 2A). In addition, HCT116-R/DLD-1-R cells had multiple, enlarged lysosomes when examined by LysoTracker staining (Fig. 2B). Meanwhile, enhanced PLD2 and Bcl-2 protein expression was found in HCT116-R/DLD-1-R cells (Fig. 2C). The same results were observed in the mRNA levels of LAMP2A and PLD2 by a RT-qPCR (Fig. 2D).

Effect of LAMP2A expression on the sensitivity to 5-FU in human CRC cell lines. Excessive LAMP2A expression is one of the major features of HCT116-R/DLD-1-R cells. It was hypothesized that the silence or overexpression LAMP2A expression in HCT116-R/DLD-1-R cells would affect the sensitivity to 5-FU. LAMP2A expression was decreased in HCT116-R/DLD-1-R cells by transfection with shLAMP2A plasmid, which resulted in decreased cell growth rate and increased 5-FU-mediated cell death (Figs. 3A and B; 4A and B). Conversely, when LAMP2A expression was increased in HCT116/DLD-1 cells by transfection with the LAMP2A overexpression plasmid, markedly increased cell growth rate and decreased 5-FU-mediated cell death was observed (Figs. 3A and B and $4 \mathrm{~A}$ and $\mathrm{B}$ ). The same results were observed following treatment with OXA and FOX (Figs. 3A and 4A). In addition, the knockdown of LAMP2A 

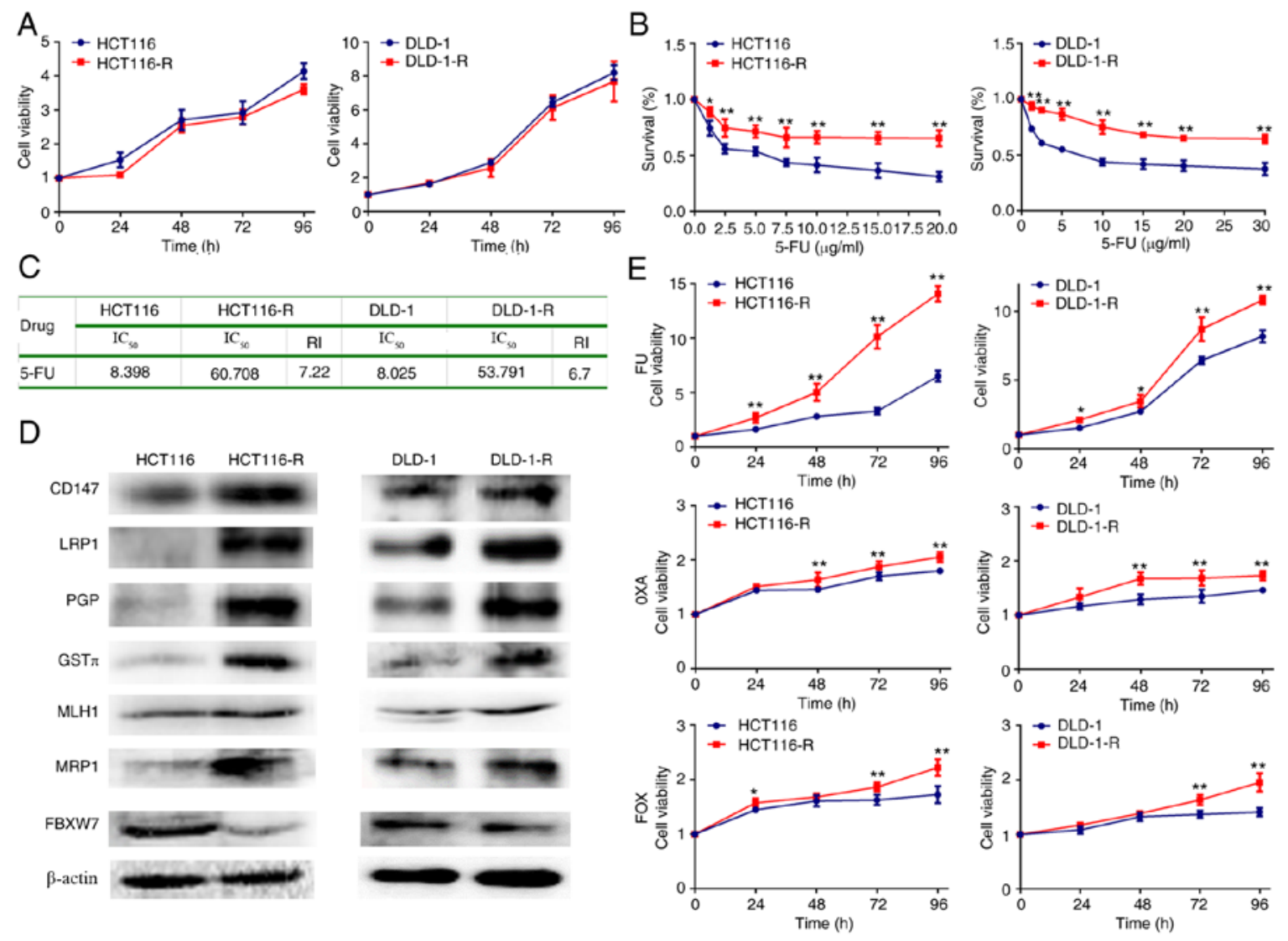

Figure 1. Generation and characterization of 5-FU-resistant cells from HCT116 and DLD-1 cells. (A) Cell proliferation curve of HCT116/DLD-1 and HCT116-R/DLD-1-R cells. (B) Cell survival curve of HCT116/DLD-1 and HCT116-R/DLD-1-R cells. (C) RI and IC 50 of 5-FU in HCT116/DLD-1 and HCT116-R/DLD-1-R cells. (D) Protein expression of chemoresistance-related genes by western blotting. (E) Cell proliferation curve of HCT116/DLD-1 and HCT116-R/DLD-1-R cells after chemotherapy drug treatment. The data represent the mean \pm standard deviation from three independent experiments. $\mathrm{P}<0.05$. ${ }^{* *} \mathrm{P}<0.01 .5-\mathrm{FU}, 5$-fluorouracil; R, resistance; RI, resistance index; $\mathrm{IC}_{50}$, inhibitory concentration; 5-FU, $10 \mathrm{mM}$; 5-FU; OXA, $10 \mathrm{mM}$ oxaliplatin; FOX, $10 \mathrm{mM}$ 5-FU + $10 \mathrm{mM}$ oxaliplatin; CD, cluster of differentiation; LRP1, lung resistance-related protein 1; PGP, P-glycoprotein 1; GST $\pi$, glutathione S-transferase $\pi$; MLH1, MutL homologue 1; MRP1; multidrug resistance-associated protein 1; FBXW7, F-box and WD40 domain protein 7.

A

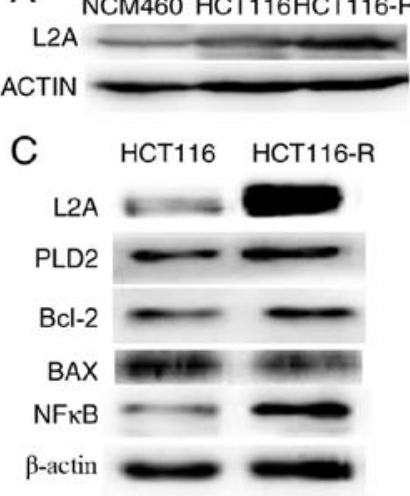

B
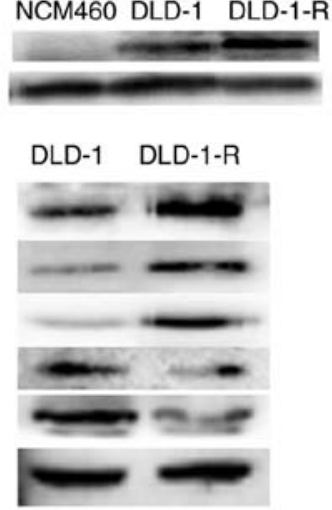
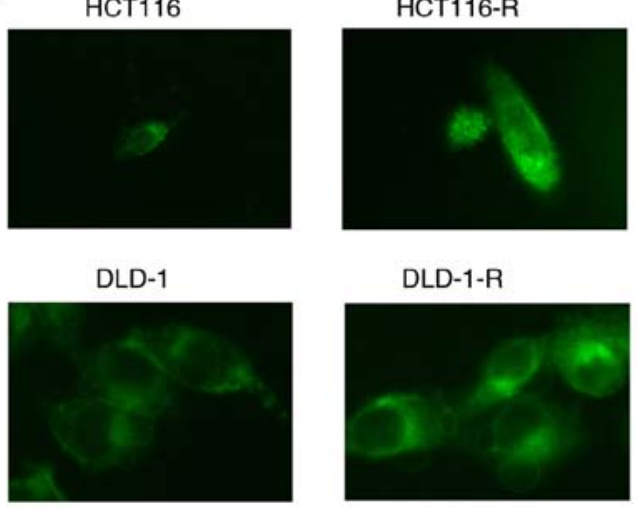

$\mathrm{D}$
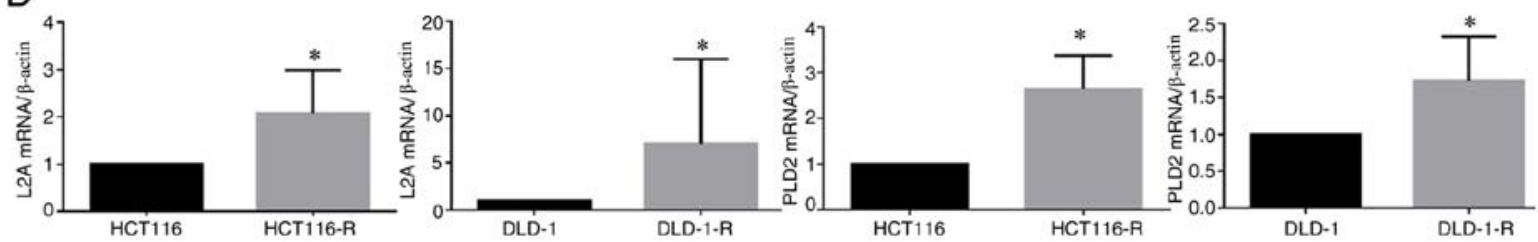

Figure 2. LAMP2A is highly expressed in human CRC cell lines. (A) LAMP2A expression in normal colonic epithelial cells, HCT116/DLD-1 and HCT116-R/ DLD-1-R cells. (B) Cells were loaded with LysoTracker-LysoGreen for $30 \mathrm{~min}$ at $37^{\circ} \mathrm{C}$. Cells were fixed and analyzed using a fluorescence microscope (x10 magnification). (C) Expression of PLD2 and Bcl-2 proteins was visualized by western blotting. (D) LAMP2A and PLD2 expression was measured by reverse transcription-quantitative PCR. The data were represented as the mean \pm standard deviation from three independent experiments, $\mathrm{P}<0.05$. LAMP2A, lysosome-associated membrane protein 2A; CRC, colorectal cancer; R, resistance; PLD2, phospholipase D2. 

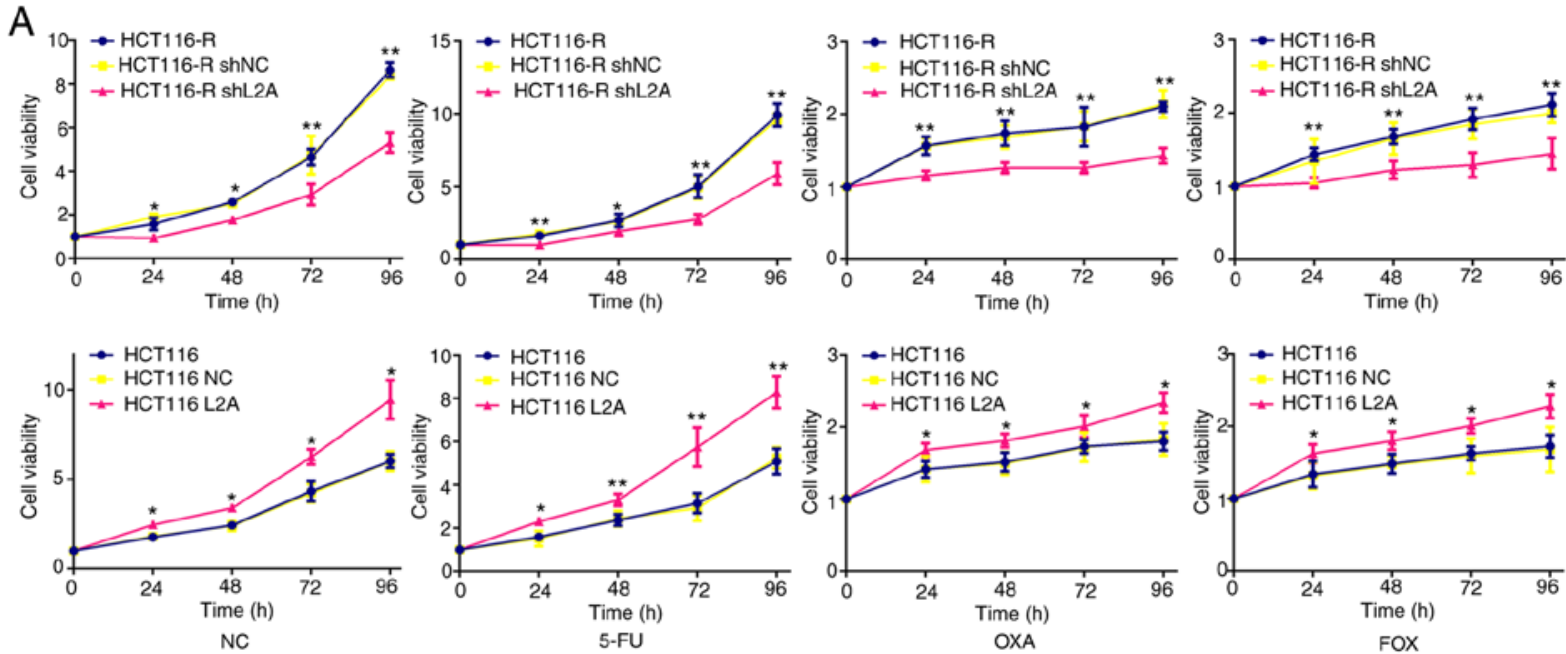

B HCT116-R HCT116-R HCT116-R C
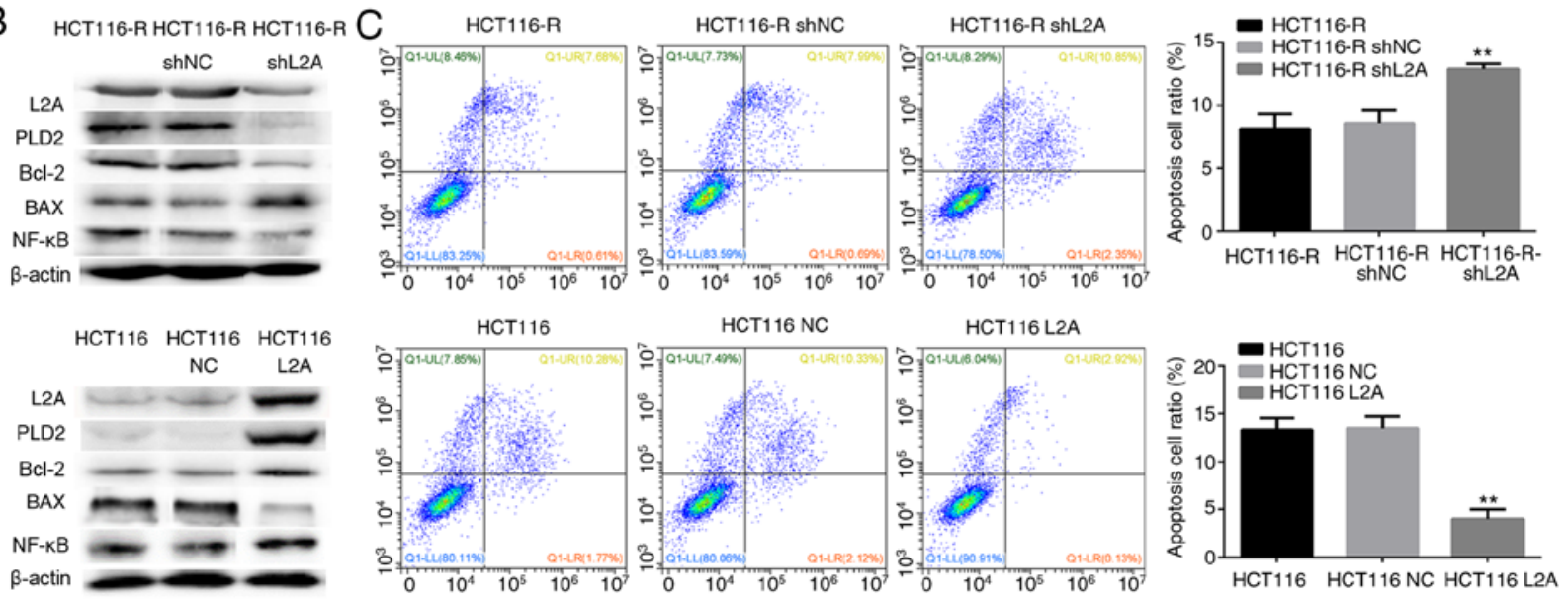

D
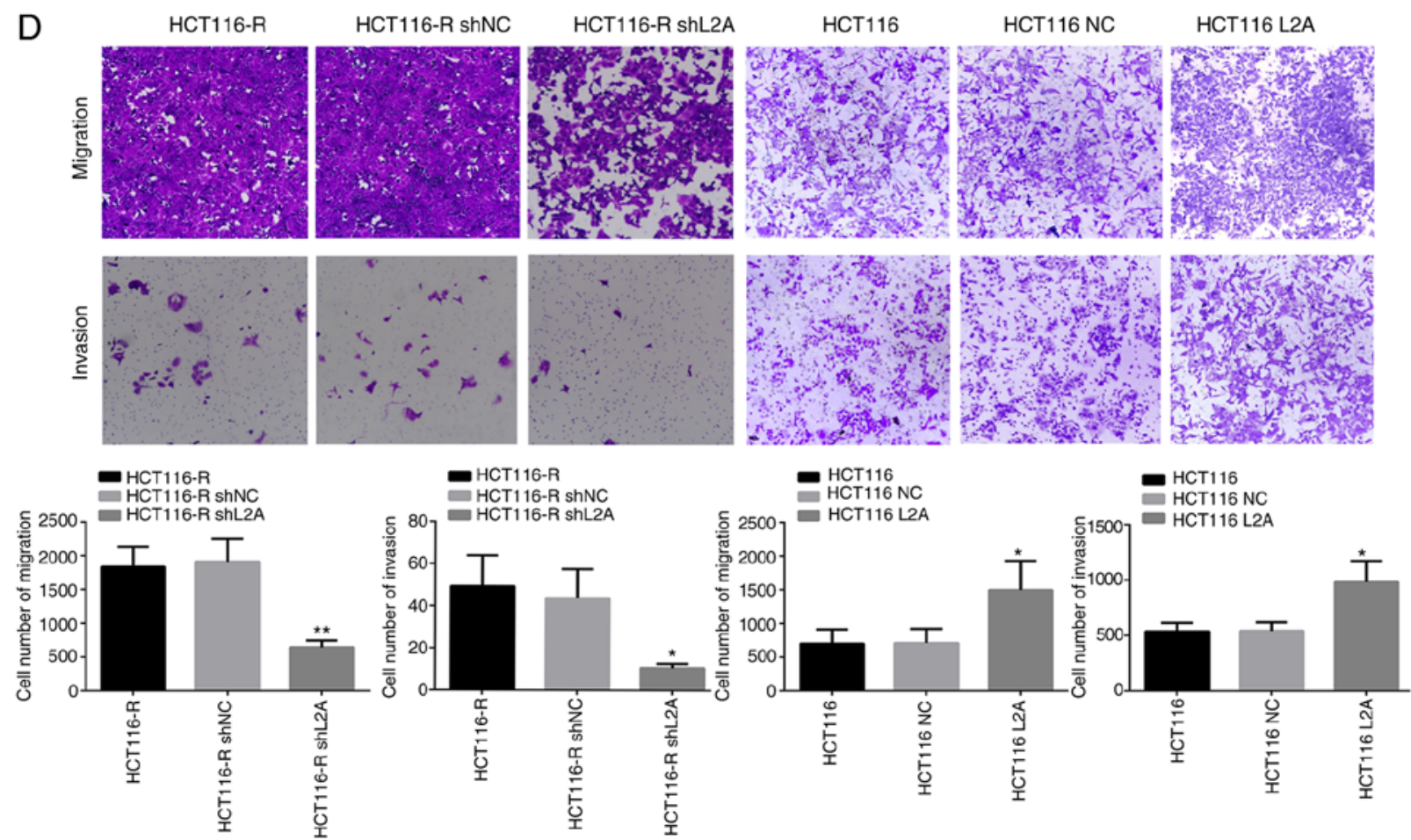

Figure 3. Effect of LAMP2A expression on the sensitivity to 5-FU in human CRC cell line. (A) Cellular viability of different drug treatments in shLAMP2A-modified HCT116-R cells or LAMP2A-modified HCT116 cells. (B) Expression of associated proteins was visualized by western blotting in shLAMP2A-modified HCT116-R cells or in LAMP2A-modified HCT116 cells. (C) Apoptosis and (D) migration and invasion and in shLAMP2A-modified HCT116-R cells or in LAMP2A-modified HCT116 cells (x10 magnification). The data represent the mean \pm standard deviation from three independent experiments. ${ }^{*} \mathrm{P}<0.05,{ }^{* *} \mathrm{P}<0.01$. LAMP2A, lysosome-associated membrane protein 2A; 5-FU, 5-fluorouracil; CRC, colorectal cancer; sh, short hairpin; R, resistance; $\mathrm{NC}$, negative control. 

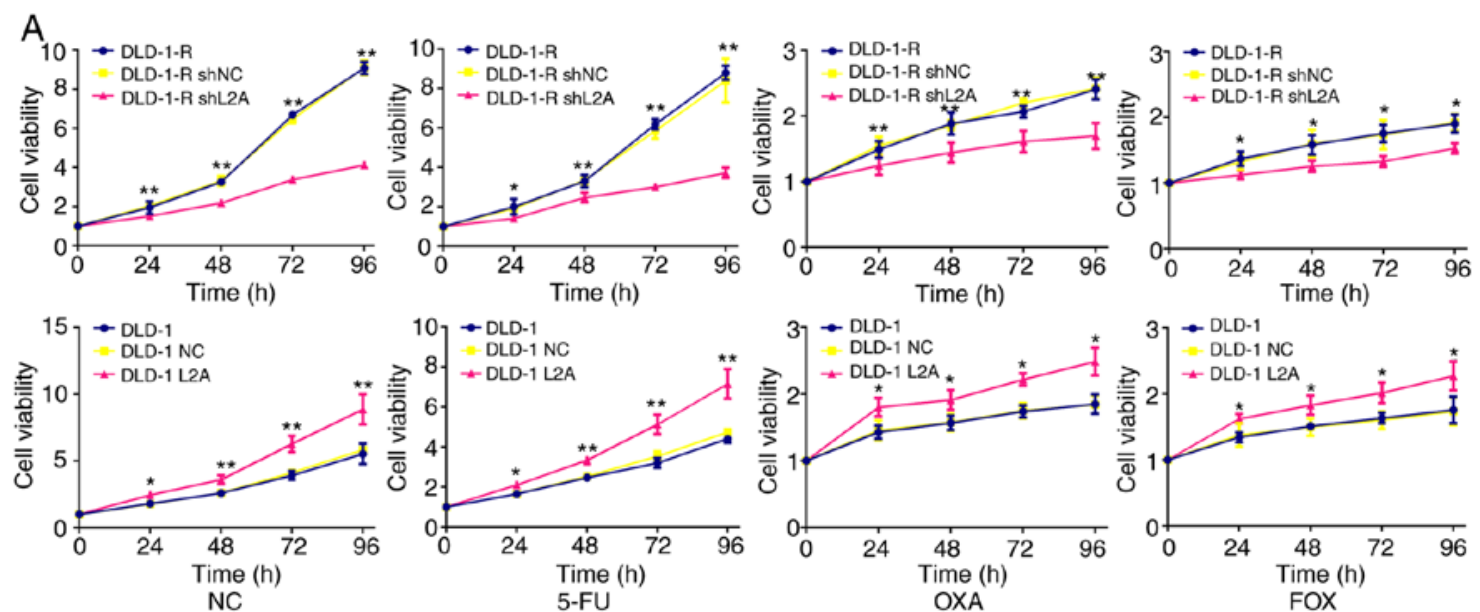

B
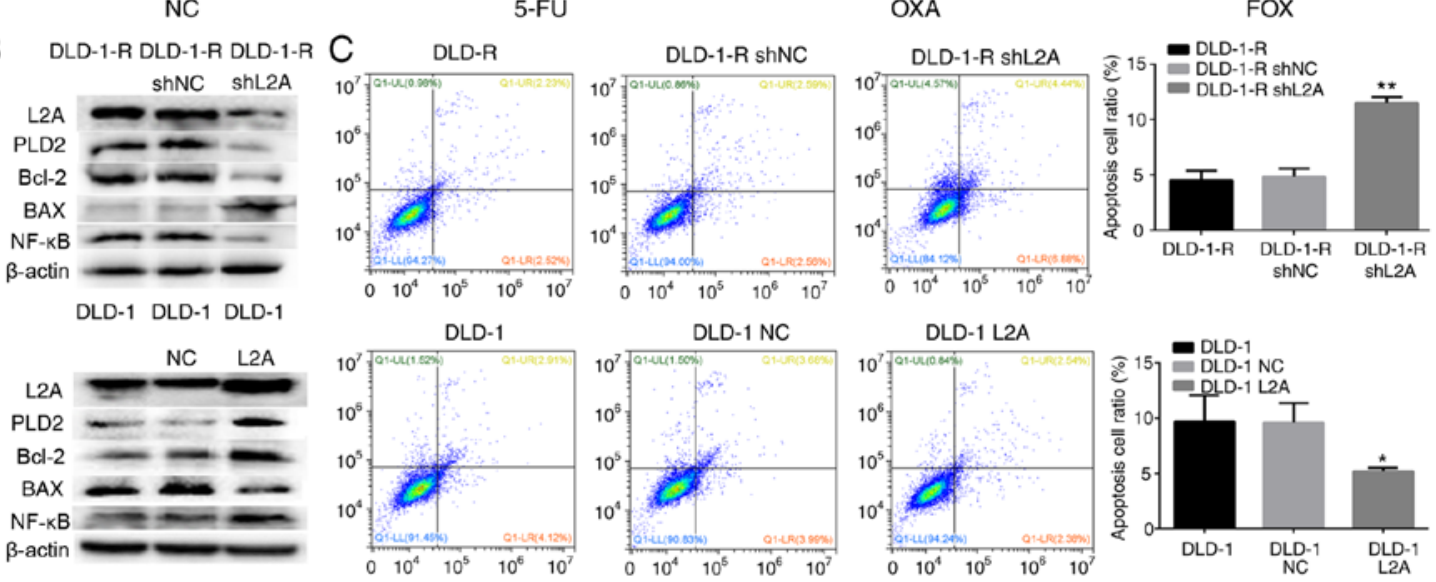

D
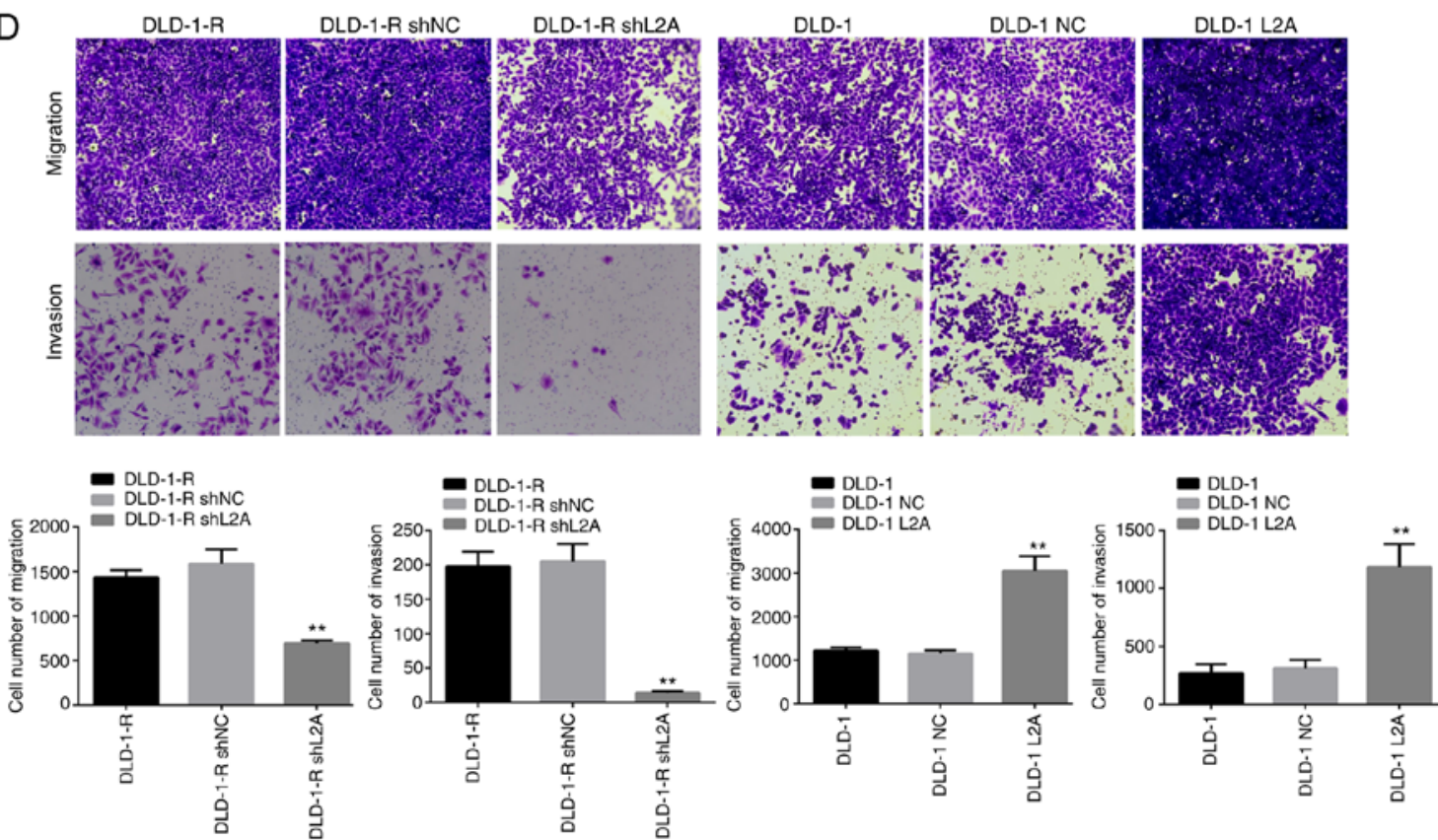

Figure 4. Effect of LAMP2A expression on the sensitivity to 5-FU in human CRC cell line. (A) Cellular viability of different drug treatments in shLAMP2A-modified DLD-1-R or LAMP2A-modified DLD-1 cells. (B) Expression of associated proteins was visualized by western blotting in shLAMP2A-modified DLD-1-R cells or in LAMP2A-modified DLD-1 cells. (C) Apoptosis and (D) migration and invasion in shLAMP2A-modified DLD-1-R cells or in LAMP2A-modified DLD-1 cells (x10 magnification). The data represent the mean \pm standard deviation from three independent experiments. ${ }^{*} \mathrm{P}<0.05,{ }^{* *} \mathrm{P}<0.01$. LAMP2A, lysosome-associated membrane protein 2A; 5-FU, 5 -fluorouracil; CRC, colorectal cancer; sh, short hairpin; R, resistance; NC, negative control; 5-FU, 10 mM; 5-FU; OXA, 10 mM oxaliplatin; FOX, 10 mM 5-FU + 10 mM oxaliplatin; PLD2, phospholipase D2.

in HCT116-R/DLD-1-R cells or overexpression of LAMP2A in HCT116/DLD-1 cells was associated with decreased or increased expression of Bcl-2. The expression of Bax was opposite (Figs. 3B and 4B). Migration and invasion were lower in cells with knockdown of LAMP2A, but apoptosis was higher. Adverse results were found in cells overexpression of 
A
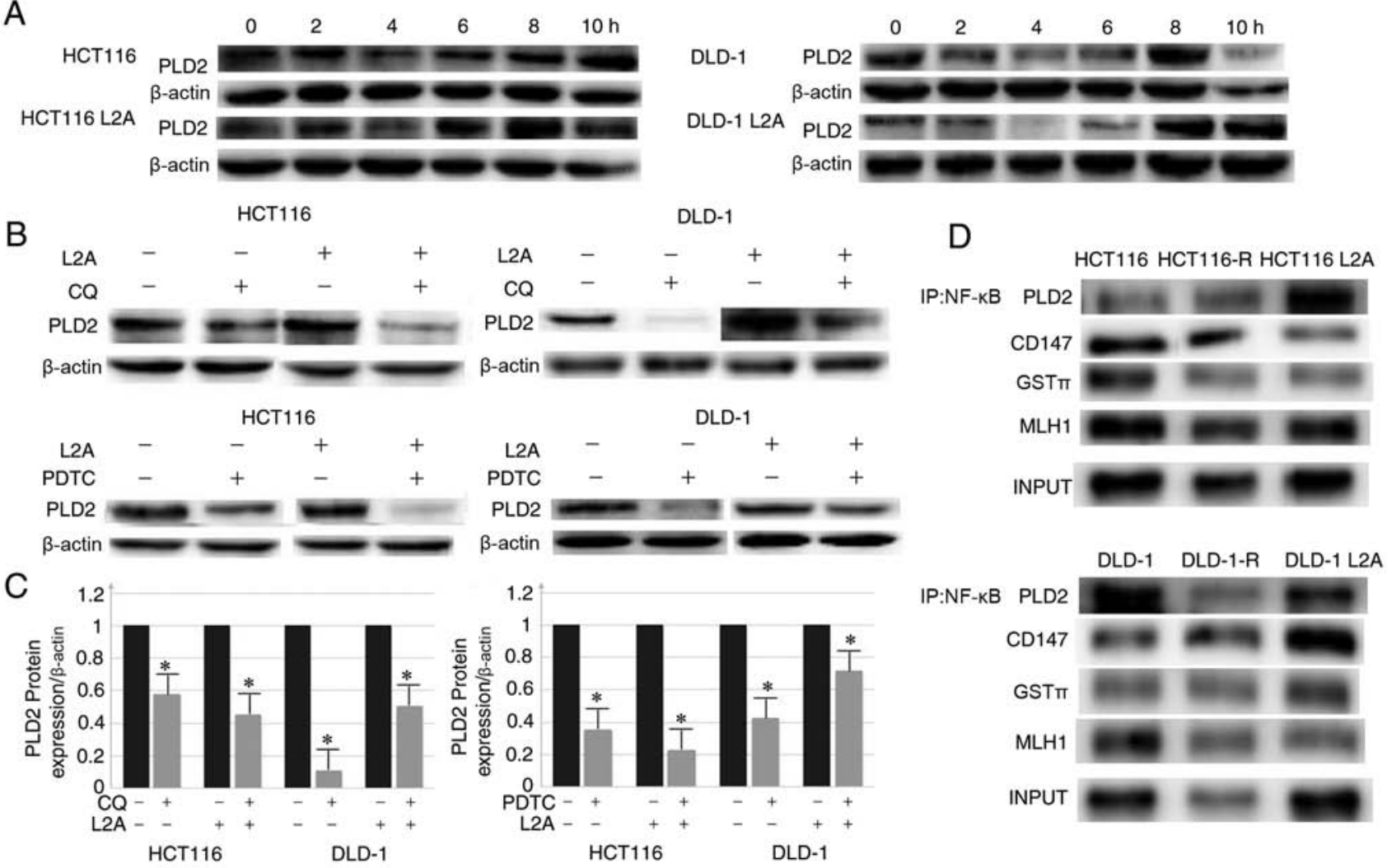

Figure 5. Inhibition of lysosomal and NF-kB p65 signaling pathways led to proliferation and decrease in expression level of PLD2 in CRC cell lines. (A) Inhibition of the lysosomal pathway with CQ $(50 \mathrm{mM})$; PLD2 first declined and then increased with the lowest point observed at $4 \mathrm{~h}$. (B and C) Inhibition of the lysosomal pathway (CQ; $50 \mathrm{Mm}, 4 \mathrm{~h}$ ) and NF- $\mathrm{kB}$ signaling pathway (PDTC; $10 \mathrm{mM} ; 2 \mathrm{~h}$ ) led to a significant reduction in the expression level of PLD2 compared with the control group. (D) Co-immunoprecipitation of NF-kB with PLD2, CD147, GST3, MLH1 in HCT116/DLD-1, HCT116-R/DLD-1-R and HCT116L2A/DLD-1L2A cells. The data represent the mean \pm standard deviation from three independent experiments. "P $<0.05$. PLD2, phospholipase D2; $\mathrm{R}$, resistance; CRC, colorectal cancer; CQ, clioquinol; PDTC, pyrrolidine dithiocarbamate; CD, cluster of differentiation; LRP1, lung resistance-related protein 1; PGP, P-glycoprotein 1; GST, glutathione S-transferase; MLH1, MutL homologue 1; IP, immunoprecipitation.

LAMP2A (Figs. 3C and D and 4C and D). Therefore, it was confirmed that HCT116-R/DLD-1-R cells can regain sensitivity to 5-FU if LAMP2A expression is reduced.

High expression of LAMP2A enhances PLD2 expression and 5-FU chemoresistance through the activation of the $N F-\kappa B$ pathway. Knockdown of LAMP2A in HCT116-R/ DLD-1-R cells or overexpression of LAMP2A in HCT116/DLD-1 cells was associated with decreased or increased expression of PLD2 and NF- $\kappa \mathrm{B}$, respectively. It was hypothesized whether high expression of LAMP2A enhanced PLD2 expression through activation of NF- $\kappa \mathrm{B}$ pathway. Therefore, HCT116-R/DLD-1-R cells were treated with CQ or PDTC to inhibit the lysosomal or $\mathrm{NF}-\kappa \mathrm{B}$ pathways. When HCT116/DLD-1 and HCT116-R/DLD-1-R cells were treated with CQ $(50 \mathrm{mM})$ and harvested at specific time points $(0,2$, 4, 6, 8 and $10 \mathrm{~h}$ ), it was identified that PLD2 first decreased and then increased (Fig. 5A). The lowest level was observed at $4 \mathrm{~h}$. Next, HCT116/DLD-1 and HCT116-R/DLD-1-R cells were treated with CQ $(50 \mathrm{mM})$ for $4 \mathrm{~h}$ and a clear and significant reduction of PLD2 was observed compared with non-treated cells in the western blot analysis (Fig. 5B and C). Notably, similar results were obtained with PDTC $(10 \mathrm{mM}, 2 \mathrm{~h}$; Fig. 5B and C). Co-immunoprecipitation experiments further confirmed the interaction of NF- $\mathrm{NB}$ with PLD2 (Fig. 5D). In addition, some drug-resistance proteins (CD147, GST3 and MLH1) were observed to be associated with $\mathrm{NF}-\kappa \mathrm{B}$ by co-immunoprecipitation experiments (Fig. 5D).

\section{Discussion}

Despite dramatic improvements in CRC diagnosis and therapeutics in recent years, a significant proportion of patients still experience recurrence and metastasis due to drug resistance, which leads to the failure of chemotherapy $(4,5,31)$. To date, 5 -FU remains a commonly used chemotherapeutic drug in cancer treatment and clinical studies (32). Despite extensive research in recent years, drug resistance remains a critical limitation to the clinical application of 5-FU and related chemotherapeutic drugs. Unfortunately, there few reliable markers available to accurately predict chemosensitivity in CRC.

Studies on CMA have indicated that the degradation of intracellular components by the lysosome can be selective (6). CMA activity is markedly upregulated in most cancer cell lines and the expression levels of CMA components, mainly LAMP2A, are elevated in a number of human tumors $(9,33,34)$. CMA can degrade anti-proliferative proteins (such as Rho family GTPase 3) (12), tumor suppressor proteins (such as phosphoprotein enriched in diabetes) (35), mutant p53 (36) and pro-apoptotic proteins such as Bcl-2 binding component 3 (37) to maintain tumor growth. It also can indirectly promote the production of survivin for the stabilization of myeloid cell 
leukemia-1 (38). CMA is also involved in the mechanism of CRC chemotherapy resistance. A previous study confirmed that 5-FU undergoes extensive deacetylation in a variety of CRC cell lines (11). It reduces the ability of histone acetyltransferase p300 and CBP to bind to chromatin and induces lysosomal degradation. The lysosomal degradation is achieved through CMA and inhibition of the degradation of p300 and CBP can enhance the effects of 5-FU and reverse drug resistance (11). This suggests that the efficacy of chemotherapy can be increased with anti-CMA therapy administered at the same time as 5-FU chemotherapy.

The present study constructed and analyzed two 5-FU-resistant cell lines from HCT-116 and DLD-1 cell lines, providing a tool to investigate the molecular pathways and detailed mechanisms that are associated with drug resistance in CRC. In the engineered 5-FU-resistant CRC cell lines, significant elevation of LAMP2A was identified; this was responsible for loss of function of LAMP2A in 5-FU-resistant $\mathrm{CRC}$ cells or gain of function in deficient cells, which rendered them sensitive or resistant to 5-FU, respectively.

Concurrently, a positive association was identified between LAMP2A and PLD2. PLD2 is one of the two isoforms of PLD in mammals, which catalyzes the hydrolysis of the diester bond of phospholipids to generate PA and the free lipid headgroup (39). PLD2 expression is elevated in a number of human tumors and is highly variable $(16,19-22)$. In CRC, the expression level of PLD2 was significantly associated with tumor size and survival of patients, which suggests that PLD2 may be a target for therapy in CRC (40).

The present study verified whether PLD2 variation exists along with LAMP2A through activation of the NF- $\mathrm{KB}$ pathway. PDTC was used to block the NF- $\mathrm{BB}$ pathway and resulted in decreased PLD2 levels. The relation between PLD2 and NF- $\mathrm{KB}$ was demonstrated by co-immunoprecipitation. PDTC, a metal chelator and antioxidant, can inhibit the activation of the NF- $\mathrm{kB}$ pathway specifically by suppressing the release of the inhibitory subunit, IкB (41). Cuervo et al (42) identified that I $\mathrm{I} B$ can be degraded by CMA during starvation. The present study found that the decrease of $I \kappa B$ in the cytoplasm was associated with an increase of LAMP2A levels. Co-immunoprecipitation experiments further confirmed the interaction of IאB with Hsc70. IkB was identified as a substrate of CMA. Therefore, when CMA was high in 5-FU-resistant $\mathrm{CRC}$ cell lines, the I $\mathrm{KB}$ level in cytoplasm decreased, resulting in increased NF- $\kappa B$ activity. Thereafter, the combination forms of PLD2 and NF- $\mathrm{BB}$ increased, which facilitated the grown of CRC cells.

CQ was used to inhibit the lysosomal pathway and it was observed that the levels of PLD2 declined early on and then increased. This might because IкB degraded though two pathways; CMA and proteasome (42). When lysosome pathway was blocked, the proteasome pathway was activated in compensation later. PLD contributes to signaling pools of PA and is under tight regulation by elaborate mechanisms and so may increase reactivity in cells (15). In addition, the present study found the interaction of NF- $\mathrm{kB}$ with some drug resistance genes, such as CD147, GST3 and MLH1, through co-immunoprecipitation. This may be another important piece of evidence that the NF- $\mathrm{KB}$ pathway is associated with drug resistance in CRC.
A significant elevation of LAMP2A was found in CRC cell lines and the increase was even higher in HCT116-R/DLD-1-R cells. The high expression of LAMP2A promoted proliferation, invasion and anti-apoptotic function of CRC cells.

In conclusion, upregulated LAMP2A expression might serve a role in tumorigenesis and growth and may be involved in drug resistance in CRC. It is a potential biomarker that indicates the aggressiveness of CRCs and, thus, may be a therapeutic target.

\section{Acknowledgements}

Not applicable.

\section{Funding}

The present study was supported by Liaoning BaiQianWan Talents Program, Award for Liaoning Distinguished Professor, a Key Scientific and Technological Project of Liaoning Province (grant no. 2015408001) and National Natural Scientific Foundation of China (grant nos. 81472544 and 81672700).

\section{Availability of data and materials}

The datasets used and/or analyzed are available from the corresponding author on reasonable request.

\section{Authors' contributions}

YX, SZ, XX and LX performed the experiments. YX analyzed the data and contributed to the manuscript writing. YX and HCZ designed the experiments and contributed to data analysis. YX and HCZ were responsible for confirming the authenticity of the data. All authors read and approved the final manuscript and agree to be accountable for all aspects of the research in ensuring that the accuracy or integrity of any part of the work are appropriately investigated and resolved.

\section{Ethics approval and consent to participate}

Not applicable.

\section{Patient consent for publication}

Not applicable.

\section{Competing interests}

The authors declare that they have no competing interests.

\section{References}

1. Siegel RL, Miller KD, Goding Sauer A, Fedewa SA, Butterly LF, Cercek A, Smith RA and Jemal A: Colorectal cancer statistics, 2020. CA Cancer J Clin 70: 145-164, 2020.

2. Takayama T, Miyanishi K, Hayashi T, Sato Y and Niitsu Y: Colorectal cancer: Genetics of development and metastasis. J Gastroenterol 41: 185-192, 2006. 
3. De Angelis R, Sant M, Coleman MP, Francisci S, Baili P, Pierannunzio D, Trama A, Visser O, Brenner H, Ardanaz E, et al: Cancer survival in Europe 1999-2007 by country and age: Results of EUROCARE-5 - a population-based study. Lancet Oncol 15: 23-34, 2014.

4. Peng SL, Thomas M, Ruszkiewicz A, Hunter A, Lawrence M and Moore J: Conventional adverse features do not predict response to adjuvant chemotherapy in stage II colon cancer ANZ J Surg 84: 837-841, 2014

5. Prados J, Melguizo C, Ortiz R, Perazzoli G, Cabeza L, Alvarez PJ, Rodriguez-Serrano F and Aranega A: Colon cancer therapy: Recent developments in nanomedicine to improve the efficacy of conventional chemotherapeutic drugs. Anticancer Agents Med Chem 13: 1204-1216, 2013

6. Kaushik S and Cuervo AM: Chaperone-mediated autophagy: A unique way to enter the lysosome world. Trends Cell Biol 22: 407-417, 2012

7. Catarino S, Pereira P and Girão H: Molecular control of chaperone-mediated autophagy. Essays Biochem 61: 663-674, 2017.

8. Kaushik S and Cuervo AM: The coming of age of chaperonemediated autophagy. Nat Rev Mol Cell Biol 19: 365-381, 2018.

9. Saha T: LAMP2A overexpression in breast tumors promotes cancer cell survival via chaperone-mediated autophagy. Autophagy 8: 1643-1656, 2012.

10. Zhang Y, Xu YY, Yao CB, Li JT, Zhao XN, Yang HB, Zhang M, Yin M, Chen J and Lei QY: Acetylation targets HSD17B4 for degradation via the CMA pathway in response to estrone. Autophagy 13: 538-553, 2017.

11. Du C, Huang D, Peng Y, Yao Y, Zhao Y, Yang Y, Wang H, Cao L, Zhu WG and Gu J: 5-Fluorouracil targets histone acetyltransferases $\mathrm{p} 300 / \mathrm{CBP}$ in the treatment of colorectal cancer. Cancer Lett 400: 183-193, 2017.

12. Zhou J, Yang J, Fan X, Hu S, Zhou F, Dong J, Zhang S, Shang Y, Jiang X, Guo H, et al: Chaperone-mediated autophagy regulates proliferation by targeting RND3 in gastric cancer. Autophagy 12: 515-528, 2016.

13. Ding ZB, Fu XT, Shi YH, Zhou J, Peng YF, Liu WR, Shi GM, Gao Q, Wang XY, Song K, et al: Lamp2a is required for tumor growth and promotes tumor recurrence of hepatocellular carcinoma. Int J Oncol 49: 2367-2376, 2016.

14. Dubois A, Furstoss N, Calleja A, erhouni M, Cluzeau T, Savy C, Marchetti S, Hamouda MA, Boulakirba S, Orange F, et al: LAMP2 expression dictates azacytidine response and prognosis in MDS/AML. Leukemia 33: 1501-1513, 2019.

15. Selvy PE, Lavieri RR, Lindsley CW and Brown HA Phospholipase D: Enzymology, functionality and chemical modulation. Chem Rev 111: 6064-6119, 2011.

16. Foster DA and Xu L: Phospholipase D in cell proliferation and cancer. Mol Cancer Res 1: 789-800, 2003.

17. Hammond SM, Altshuller YM, Sung TC, Rudge SA, Rose K, Engebrecht J, Morris AJ and Frohman MA: Human ADP ribosylation factor-activated phosphatidylcholine-specific phospholipase D defines a new and highly conserved gene family. J Biol Chem 270: 29640-29643, 1995.

18. Colley WC, Sung TC, Roll R, Jenco J, Hammond SM, Altshuller Y, Bar-Sagi D, Morris AJ and Frohman MA: Phospholipase D2, a distinct phospholipase D isoform with novel regulatory properties that provokes cytoskeletal reorganization. Curr Biol 7: 191-201, 1997.

19. Henkels KM, Boivin GP, Dudley ES, Berberich SJ and Gomez-Cambronero J: Phospholipase D (PLD) drives cell invasion, tumorgrowth and metastasis in a human breast cancer xenograph model. Oncogene 32: 5551-5562, 2013.

20. Uchida N, Okamura S and Kuwano H: Phospholipase D activity in human gastric carcinoma. Anticancer Res 19: 671-675, 1999.

21. Diaz-Aragon R, Ramirez-Ricardo J, Cortes-Reynosa P, Simoni-Nieves A, Gomez-Quiroz LE and Perez Salazar E: Role of phospholipase D in migration and invasion induced by linoleic acid in breast cancer cells. Mol Cell Biochem 457: 119-132, 2019

22. Liu M, Du K, Jiang B and Wu X: High expression of phospholipaseD2 induced by hypoxia promotes proliferation of colon cancer cells through activating NF- $\kappa$ Bp65 signaling pathway. Pathol Oncol Res 26: 281-290, 2018.

23. Fiucci G, Czarny M, Lavie Y, Zhao D, Berse B, Blusztajn JK and Liscovitch M: Changes in phospholipaseD isoform activity and expression in multidrug-resistant human cancer cells. Int J Cancer 85: 882-888, 2000.
24. Livak KJ and Schmittgen TD: Analysis of relative gene expression data using real-time quantitative PCR and the 2(-Delta Delta C(T)) method. Methods 25: 402-408, 2001.

25. Kuang YH, Chen X, Su J, Wu LS, Liao LQ, Li D, Chen ZS and Kanekura T: RNA interference targeting the CD147 induces apoptosis of multi-drug resistant cancer cells related to XIAP depletion. Cancer Lett 276: 189-195, 2009.

26. Nakayama K, Kanzaki A, Ogawa K, Miyazaki K, Neamati N and Takebayashi Y: Copper-transporting P-type adenosine triphosphatase (ATP7B) as a cisplatin based chemoresistance marker in ovarian carcinoma: Comparative analysis with expression of MDR1, MRP1, MRP2,LRP and BCRP. Int J Cancer 101: 488-495, 2002

27. Ściskalska M and Milnerowicz H: The role of GST $\pi$ isoform in the cells signalling and anticancer therapy. Eur Rev Med Pharmacol Sci 24: 8537-8550, 2020.

28. He J, He J, Min L, He Y, Guan H, Wang J and Peng X: Extracellular vesicles transmitted miR-31-5p promotes sorafenib resistance by targeting MLH1 in renal cell carcinoma. Int J Cancer 146: 1052-1063, 2020.

29. Germano G, Lamba S, Rospo G, Barault L, Magrì A, Maione F, Russo M, Crisafulli G, Bartolini A, Lerda G, et al: Inactivation of DNA repair triggers neoantigen generation and impairs tumour growth. Nature 552: 116-120, 2017.

30. Xiao G, Li Y, Wang M, Li X, Qin S, Sun X, Liang R, Zhang B, Du N, Xu C, et al: FBXW7 suppresses epithelialmesenchymal transition and chemo-resistance of non-small-cell lung cancer cells by targeting snail for ubiquitin-dependent degradation. Prolif 51: e12473, 2018.

31. Rezasoltani S,Asadzadeh-Aghdaei H,Nazemalhosseini-MojaradE, Dabiri H, Ghanbari R and Zali MR: Gut microbiota, epigenetic modification and colorectal cancer. Iran J Microbiol 9: 55-63, 2017.

32. Skarkova V, Kralova V, Vitovcova B and Rudolf E: Selected aspects of chemoresistance mechanisms in colorectal carcinoma-A focus on epithelial-to-mesenchymal transition, autophagy, and apoptosis. Cells 8: 234, 2019.

33. Kon M, Kiffin R, Koga H, Chapochnick J, Macian F, Varticovski L and Cuervo AM: Chaperone-mediated autophagy is required for tumor growth. Sci Transl Med 3: 109ra117, 2011.

34. Li L, Fang R, Liu B, Shi H, Wang Y, Zhang W, Zhang X and Ye L: Deacetylation of tumor-suppressor MST1 in Hippo pathway induces its degradation through HBXIP-elevated HDAC6 in promotion of breast cancer growth. Oncogene 35: 4048-4057, 2016.

35. Quintavalle C, Di Costanzo S, Zanca C, Tasset I, Fraldi A, Incoronato M, Mirabelli P, Monti M, Ballabio A, Pucci P, et al: Phosphorylation-regulated degradation of the tumor-suppressor form of PED by chaperone-mediated autophagy in lung cancer cells. J Cell. Physiol 229: 1359-1368, 2014.

36. Vakifahmetoglu-Norberg H, Kim M, Xia HG, Iwanicki MP, Ofengeim D, Coloff JL, Pan L, Ince TA, Kroemer G, Brugge JS and Yuan J: Chaperone-mediated autophagy degrades mutant p53. Genes Dev 27: 1718-1730, 2013.

37. Xie W, Zhang L, Jiao H, Guan L, Zha J, Li X, Wu M, Wang Z, Han J and You H: Chaperone-mediated autophagy prevents apoptosis by degrading BBC3/PUMA. Autophagy 11: $1623-1635,2015$.

38. Suzuki J, Nakajima W, Suzuki H, Asano Y and Tanaka N: Chaperone-mediated autophagy promotes lung cancer cell survival through selective stabilization of the pro-survival protein, MCL1. Biochem Biophys Res Commun 482: 1334-1340, 2017.

39. Yao Y, Wang X, Li H, Fan J, Qian X, Li H and Xu Y: Phospholipase D as a key modulator of cancer progression. Biol Rev Camb Philos Soc 95: 911-935, 2018.

40. Saito M, Iwadate M, Higashimoto M, Ono K, Takebayashi Y and Takenoshita S: Expression of phospholipase D2 in human colorectal carcinoma. Oncol. Rep 18: 1329-1334, 2017.

41. Li H, Sun Y, Liang J, Fan Y and Zhang XD: pH-Sensitive pullulan-DOX conjugate nanoparticles for co-loading PDTC to suppress growth and chemoresistance of hepatocellular carcinoma. J Mater Chem B 3: 8070-8078, 2015.

42. Cuervo AM, Hu W, Lim B and Dice JF: IkappaB is a substrate for a selective pathway of lysosomal proteolysis. Mol Biol Cell 9: 1995-2010, 1998

This work is licensed under a Creative Commons Attribution-NonCommercial-NoDerivatives 4.0 International (CC BY-NC-ND 4.0) License. 